Marquette University

e-Publications@Marquette

School of Dentistry Faculty Research and

Publications

Dentistry, School of

$7-1-2005$

\title{
Prevention of Periodontal Diseases
}

Andrew R. Dentino

Marquette University, andrew.dentino@marquette.edu

Moawia M. Kassab

Marquette University, moawia.kassab@marquette.edu

Erica J. Renner

Marquette University

Accepted version. Dental Clinics of North America, Vol. 49, No. 3 (July 2005): 573-594. DOI. (C) 2005 Elsevier B.V. Used with permission. 
Marquette University

\title{
e-Publications@Marquette
}

\section{Dentistry Faculty Research and Publications/School of Dentistry}

This paper is NOT THE PUBLISHED VERSION; but the author's final, peer-reviewed manuscript.

The published version may be accessed by following the link in the citation below.

FEMS Microbiology Letters, Vol. 206, No. 1 (2002): 9-18. DOI. This article is (C) Oxford University Press and permission has been granted for this version to appear in e-Publications@Marquette. Oxford University Press does not grant permission for this article to be further copied/distributed or hosted elsewhere without the express permission from Oxford University Press.

\section{Prevention of Periodontal Diseases}

\author{
Andrew R. Dentino \\ Department of Surgical Sciences, School of Dentistry, Marquette University, Milwaukee, WI \\ Moawia M. Kassab \\ Department of Surgical Sciences, School of Dentistry, Marquette University, Milwaukee, WI \\ Erica J. Renner \\ Department of Surgical Sciences, School of Dentistry, Marquette University, Milwaukee, WI
}

Prevention of periodontal diseases, including gingivitis and periodontitis, has been defined as a multistage process with primary, secondary, and tertiary components. 1 Primary prevention involves preventing inception of disease and includes the concept of health promotion and protection strategies. These health promotion strategies, aimed at enabling groups or individuals to control and improve their health, include providing oral hygiene education and protection strategies such as fluoridation. In developed nations, dentistry has been successful in these primary prevention areas. This success is illustrated by improvements in attitudes toward the importance of oral hygiene and the provision of fluoridated water supplies. ${ }^{2}, \underline{3}$ Secondary disease prevention aims to limit the impact of disease by way of early diagnosis and treatment, thereby stopping disease progression in its earliest stages. The concept of tertiary disease 
prevention is focused on the rehabilitation of the functional limitations that arise due to the disabilities encountered after advanced disease and includes such things as implants and prosthetic restoration of missing teeth.

Because the ultimate goal is to maintain the dentition over a lifetime in a state of health, comfort, and function in an esthetically pleasing presentation, this article focuses on the first two stages of periodontal disease prevention as they relate to gingivitis and periodontitis. Because these diseases are biofilm mediated and oral hygiene is important in all stages of prevention, certain concepts discussed here can and should be applied to all three phases of disease prevention. This article discusses risk assessment, mechanical plaque control, chemical plaque control, current clinical recommendations for optimal prevention, and future preventive strategies.

\section{Risk assessment as an aid in prevention}

The idea of applying risk assessment information to supportive periodontal care after thorough surgical or nonsurgical periodontal therapy is not new or untested. Axelsson and coworkers,$\underline{5,6}$ demonstrated that this approach essentially eliminates the recurrence of caries and periodontal disease. Until recently, however, there has not been any validated and generally accepted tool for risk assessment. Through the 1960s, the concept of varying susceptibility to periodontitis was not widely accepted because early epidemiologic studies suggested that the disease was essentially pandemic in adults. $\underline{\underline{z}} \underline{\underline{8}}$ Subsequent experimental work on animals demonstrated variability in disease expression,,$-\frac{9}{}$ and more precise human population studies showed substantially lower prevalence rates for moderate to advanced periodontitis. $\stackrel{10}{ }$ These findings strongly suggested that differing susceptibilities for periodontal disease existed within a population. Much work has been done since that time to define local, environmental, and genetic factors that place individuals at a higher risk for developing periodontitis. $\underline{11}, \underline{12}, \underline{13}, \underline{14}$

A risk factor is defined as some aspect of personal behavior or lifestyle, an environmental exposure, or an inherited characteristic that based on epidemiologic evidence is known to be hazardous to one's health and well-being. $\frac{15}{\text { The }}$ Thesence of a risk factor increases the probability of developing the disease and represents a possible target for prevention or therapy. Although it is beyond the scope of this article to review the evidence that has accumulated over the last 2 decades regarding identification of risk factors and their strength of association with periodontitis, there are several factors that have repeatedly been documented. Examples of such risk factors include cigarette smoking, uncontrolled diabetes, irregular dental care, and plaque in the presence of attachment loss. This article focuses on recent research efforts to quantify the risk assessment because this represents a major step forward in the attempt to tailor preventive strategies for individuals.

As dentistry and periodontics begin to transition from a repair model of oral health care to a wellness model, the need to be able to predictably quantify levels of risk is crucial. In the last 
World Workshop of Periodontics, the consensus report on prevention stated that the incorporation of risk assessment models for prevention of periodontal disease is an important goal. The concept of continuous multilevel risk assessment has developed and has been promoted as an important, if not essential, factor in proper patient assessment as part of treatment planning and reassessment during maintenance. $\frac{16}{}$ One of the consistent therapeutic goals in the American Academy of Periodontology's Parameters of Care is to reduce or eliminate contributing risk factors for gingivitis and periodontitis. 17 Moreover, the latest American Academy of Periodontology position paper on periodontal maintenance recommends that dental professionals should counsel people on the control of risk factors. $\underline{18}$ The actual assessment and application of risk levels in prevention and management of periodontitis, however, is in its infancy. Although there are odds ratios and relative risk levels published for a variety of exposures as a crude means to assess the importance of each factor, there is currently little to no information on the interactions of these different risk factors. Clearly, not all of the relevant risk factors have been uncovered.

Recently, a few clinical risk assessment approaches or tools have been promoted in the literature. One tool is a relatively simple questionnaire $\underline{\underline{19}}$ that provides a vague but individual risk profile for the clinician and an educational tool for communication with the patient. A more sophisticated instrument employs a continuous multilevel risk assessment that incorporates the consideration of subject, tooth, and site risk evaluations. $\underline{16}$ This approach generates functional diagrams that provide a more objective means of quantifying an individual's risk (Fig. 1). $\underline{16}$ Depending on the area of the polygon, a patient may fall into low-, moderate-, or high-risk categories. The patient's individual periodontal risk assessment is low if all parameters fall within the low-risk categories or if only one category in the moderate-risk range (Fig. 2). A moderate periodontal risk assessment shows at least two parameters in the moderate category, with a maximum of one parameter in the high-risk area (Fig. 3). A patient with a high periodontal risk assessment has at least two parameters in the high-risk category (Fig. 4). Although this model still needs to be validated, it provides an objective quantification of risk into three categories. This assessment could provide justification for more or less aggressive preventive care. 


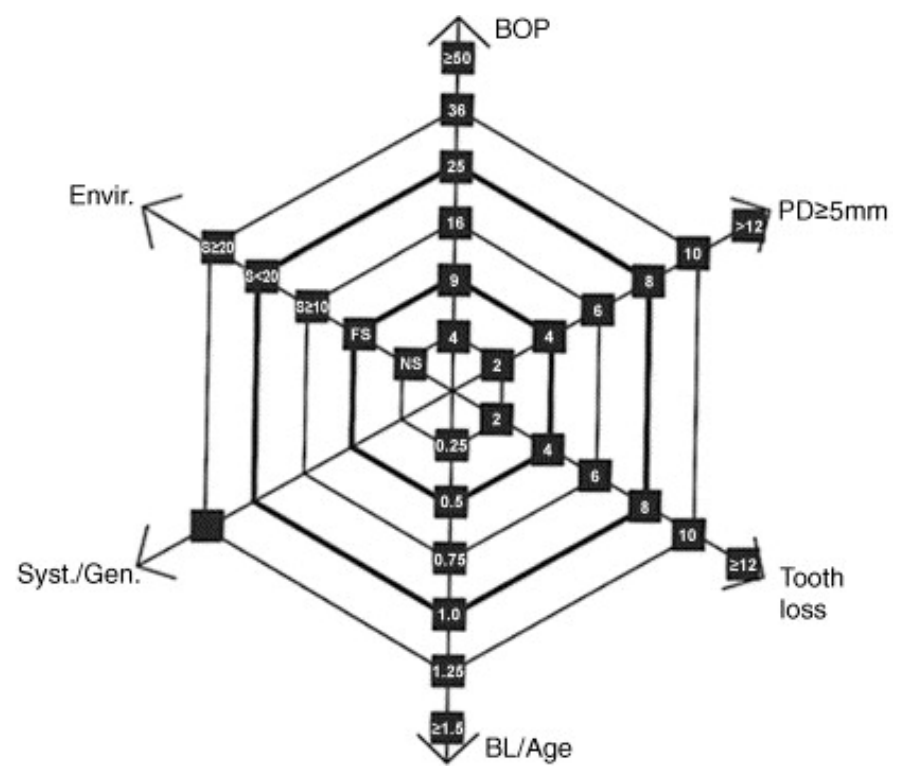

Fig. 1. Functional diagram to evaluate the patient's risk for recurrence of periodontitis. Each vector represents one risk factor or indicator with an area of relatively low risk, an area of moderate risk, and an area of high risk for disease progression. All factors have to be evaluated together; therefore, the area of relatively low risk is found within the center circle of the polygon, whereas the area of high risk is found outside the periphery of the second ring in bold. Between the two rings in bold, there is the area of moderate risk. BL, bone loss; BOP, bleeding on probing; Envir., environment; FS, frequent smoker; NS, nonsmoker; PD, pocket depth; S, smoker; Syst./Gen., systemic/general. (From Lang NP, Bragger U, Salvi G, et al.

Supportive periodontal therapy (SPT). In: Lindhe J, Karring T, Lang NP, editors. Clinical periodontology and implantology. 4th edition. Oxford (England): Blackwell Munksgaard; 2003. p. 788; with permission.)

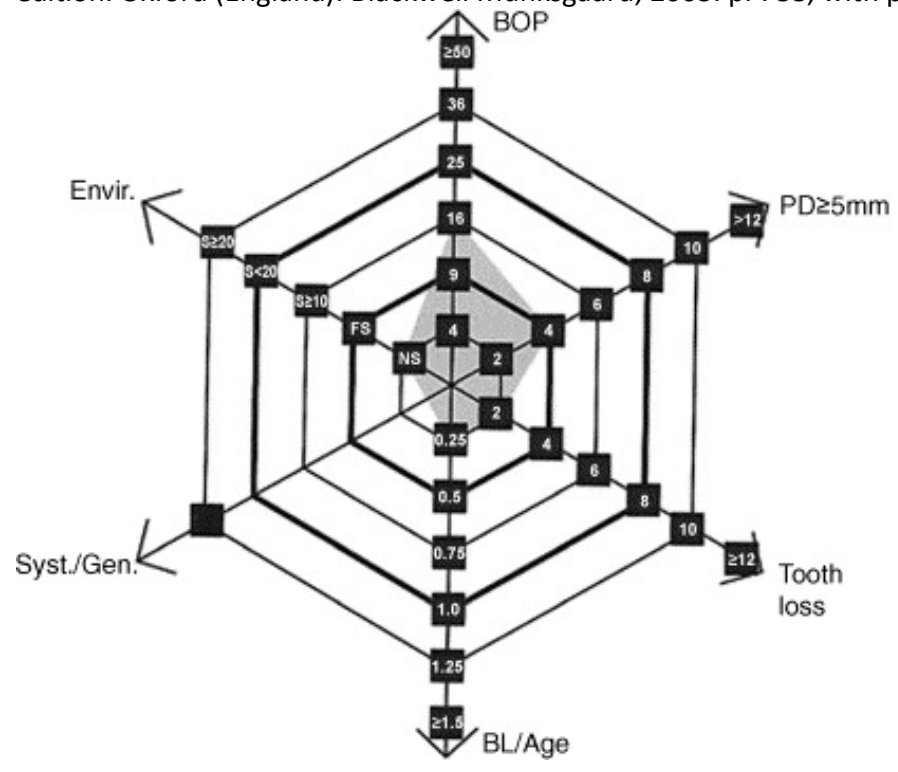

Fig. 2. Functional diagram of a low-risk maintenance patient. Bleeding on probing (BOP) is $15 \%$, four residual pockets $\geq 5 \mathrm{~mm}$ are diagnosed, two teeth have been lost, the bone factor in relation to age is 0.25 , no systemic factor is known, and the patient is a nonsmoker. BL, bone loss; Envir., environment; FS, frequent smoker; NS, nonsmoker; PD, pocket depth; S, smoker; Syst./Gen., systemic/general. (From Lang NP, Bragger U, Salvi G, et al. Supportive periodontal therapy (SPT). In: Lindhe J, Karring T, Lang NP, editors. Clinical periodontology and implantology. 4th edition. Oxford (England): Blackwell Munksgaard; 2003. p. 788; with permission.) 


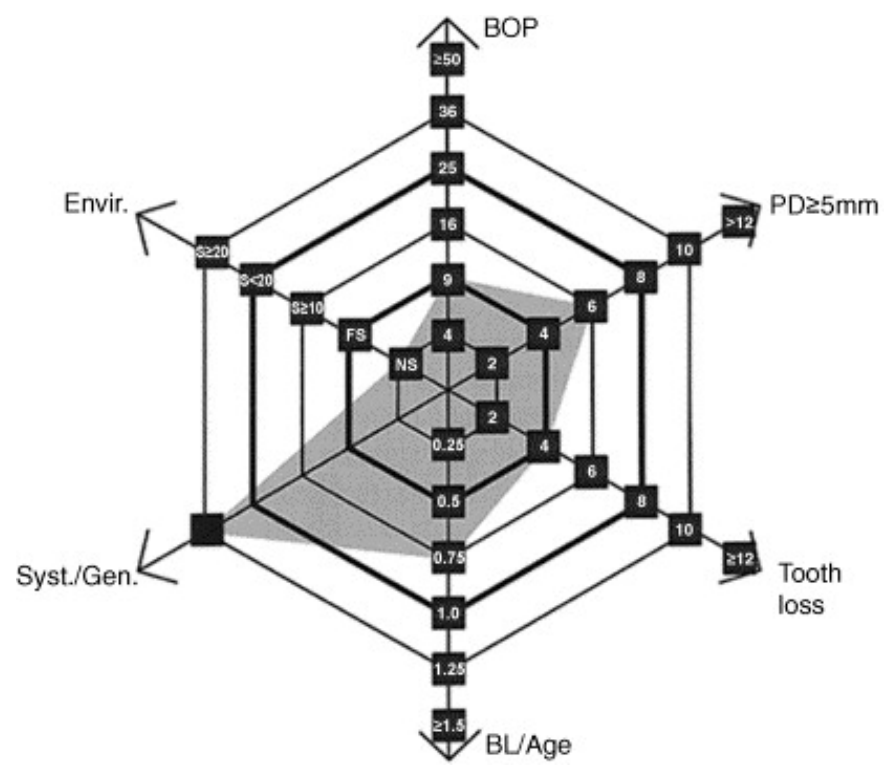

Fig. 3. Functional diagram of a medium-risk maintenance patient. Bleeding on probing (BOP) is $9 \%$, six residual pockets $\geq 5 \mathrm{~mm}$ are diagnosed, four teeth have been lost, the bone factor in relation to age is 0.75 , the patient has type I diabetes mellitus, and the patient is a nonsmoker. BL, bone loss; Envir., environment; FS, frequent smoker; NS, nonsmoker; PD, pocket depth; S, smoker; Syst./Gen., systemic/general. (From Lang NP, Bragger U, Salvi G, et al. Supportive periodontal therapy (SPT). In: Lindhe J, Karring T, Lang NP, editors. Clinical periodontology and implantology. 4th edition. Oxford (England): Blackwell Munksgaard; 2003. p. 799; with permission.)

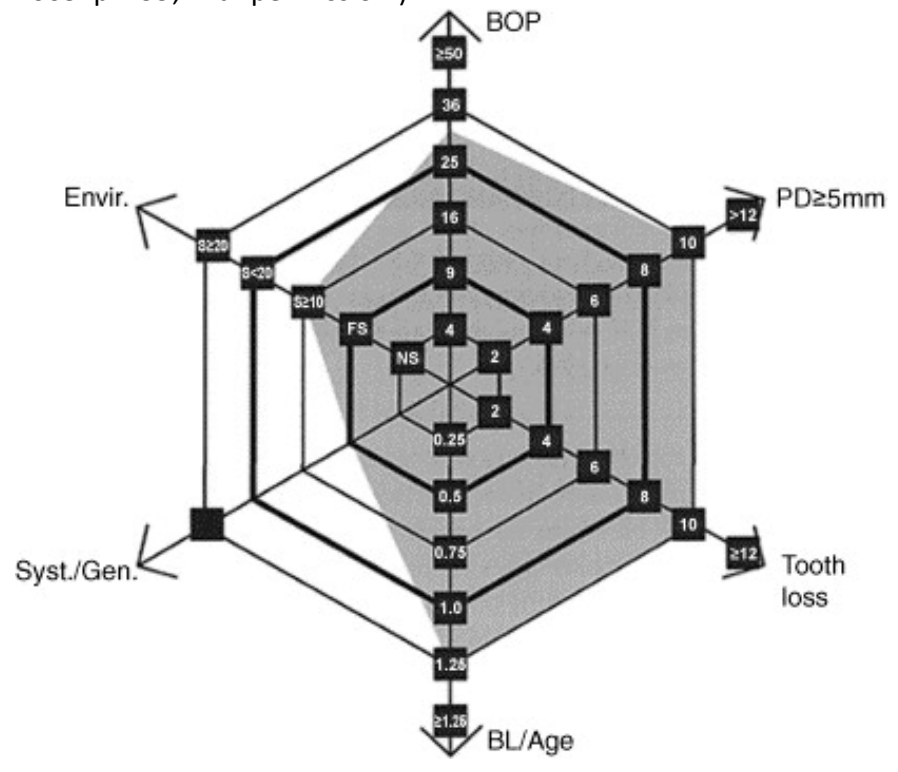

Fig. 4. Functional diagram of a high-risk maintenance patient. Bleeding on probing (BOP) is $32 \%, 10$ residual pockets $\geq 5 \mathrm{~mm}$ are diagnosed, 10 teeth have been lost, the bone factor in relation to age is 1.25, no systemic factor is known, and the patient is an occasional smoker. BL, bone loss; Envir., environment; FS, frequent smoker; NS, nonsmoker; PD, pocket depth; S, smoker; Syst./Gen., systemic/general. (From Lang NP, Bragger U, Salvi G, et al. Supportive periodontal therapy (SPT). In: Lindhe J, Karring T, Lang NP, editors. Clinical periodontology and implantology. 4th edition. Oxford (England): Blackwell Munksgaard; 2003. p. 799; with permission.)

\section{Using a different multifactorial model, Page and coworkers ${ }^{22}$ developed the "Periodontal Risk Calculator" (PRC). The PRC incorporates mathematic algorithms that are based on nine known}


risk factors: age, smoking history, diabetes diagnosis, history of periodontal surgery, pocket depth, furcation involvements, restorations or calculus below the gingival margin, radiographic bone height, and vertical bone lesions. This Web-based instrument can be accessed at http://www.previser.com, and to the authors' knowledge, provides the first validated tool to objectively quantify risk. Because risk assessments based on subjective expert opinion have been shown to vary too much to be useful in everyday clinical decision making [20], the development of the PRC may well represent a major step forward in the transition from the surgical/repair model of dentistry to the wellness or medical model of patient care. Data suggest that expert clinicians in the United States and Europe appear to base most of their risk assessment on severity of disease at presentation rather than on factors such as smoking, diabetic status, and poor oral hygiene. $\frac{20}{2}$ Moreover, it has been observed that "risk scores generated for individual patients by subjective expert clinician opinion are highly variable and could result in the misapplication of treatment for some patients". $\underline{\underline{21}}$ Overtreatment or undertreatment of periodontal diseases may be the result of subjectively forming such opinions.

Using a clinical patient data set from the VA Dental Longitudinal Study of Oral Health and Disease, Page and coworkers $\underline{22}, \underline{23}$ retrospectively assigned risk scores to each of the 523 subjects on a 1 (lowest) to 5 (highest) risk scale using information from the baseline examination. They subsequently assessed radiographic bone loss and tooth loss over the next 15 years. The mean percentage of bone loss followed a consistent pattern from least bone loss in the low-risk category to greatest bone loss in the highest risk category $(2<3<4<5)$. Several measures of tooth loss over time showed a similar relationship. Clearly, this approach to validation had weaknesses that included the retrospective nature of the study, the lack of enough low-risk subjects (periodontal risk assessment $=1$ ) to allow for the full range of risk levels to be validated, and the lack of data on why teeth were lost. In addition, for teeth without periodontal disease at baseline, the PRC did not appear to discriminate between risk levels. This study, however, demonstrated the ability of the PRC to "predict" with accuracy and validity periodontal deterioration and even tooth loss for teeth with periodontal disease at baseline.

In addition to providing a quick and objective risk assessment, the PRC provides a periodontal diagnosis, a quantitative disease score from 1 to 100, and treatment options based on the current American Academy of Periodontology standards of care. If this technology catches on, it may have a substantial impact on the dental profession. The PRC would provide a useful tool for individual patient assessment and may help sort out cost-effective treatments and even suggest rational approaches to preventive measures. Accurate and objective risk prediction should provide dentistry the ability to make serious strides in moving toward a wellness model of patient care. It has the potential to substantially improve the allocation of health care dollars by reducing the overtreatment of low-risk patients and applying more aggressive preventive strategies to high-risk patients. 


\section{Mechanical plaque control}

Successful primary or secondary prevention is based on two major factors, the first being proper, thorough treatment during active therapy and the second being patient compliance with daily plaque removal and regular professional supportive care. Because other articles in this issue of the Dental Clinics of North America deal with active surgical and nonsurgical treatments to eliminate disease, the current authors confine themselves to addressing current concepts in primary prevention of gingivitis and periodontitis and the personal and professional supportive methods to avoid recurrence after active therapy is finished. The authors' premise is that proper and thorough active treatment means leaving the patient with a maintainable periodontium, which can be accomplished with nonsurgical therapy in the disease control phase of treatment or after the surgical corrective phase.

There is overwhelming evidence for the direct cause-and-effect relationship between the formation and accumulation of supragingival plaque and the development of gingivitis. It is also generally accepted that the loss of attachment and alveolar bone that defines periodontitis is preceded by gingivalinflammation and subgingival plaque maturation.

It has been estimated that in a periodontitis patient with a full complement of teeth (28 teeth/168 sites) only $6 \%$ or less of these sites exhibit tissue destruction at any given time. $\frac{24}{2}$ Although only a small percentage of gingivitis sites may progress to periodontitis, it still cannot be discerned which inflamed sites are actively breaking down. Traditionally, the default approach has been to try to eliminate all plaque-induced inflammation, particularly in subjects who have shown a susceptibility to a destructive periodontal inflammation. The first line of defense against plaque-induced gingivitis has always been daily meticulous mechanical plaque removal supplemented by periodic professional mechanical tooth cleaning.

\section{Toothbrushing: manual versus powered}

Toothbrushing has played the major role in daily plaque control in developed nations for over 60 years. According to the Lemelson-MIT Invention Index at the Massachusetts Institute of Technology, when Americans were asked to list the five inventions that they believed they could not live without, the toothbrush was more appreciated than the car, the personal computer, the cell phone, and the microwave oven. $\underline{24 a}$

Many novel manual toothbrush designs and methods of brushing have been described in the literature, with no one design or method showing a clear superiority. There is no consensus on the optimal frequency of toothbrushing, but it is clear that the average person is not very efficient or thorough in daily plaque removal. $\underline{25}$ Hawkins et al. $\underline{26}$ and Beals et al. $\underline{27}$ showed that most subjects spend less than a minute brushing their teeth with a manual toothbrush. It therefore seems reasonable for clinicians to ask whether it is time to start recommending powered brushes with automatic timers to moderate- and high-risk patients.

When Van der Weijden and coworkers $\underline{28,29}$ performed professional plaque removal on subjects for varying duration using a manual or an oscillating/rotating powered brush, they 
demonstrated that manual brushing, even after 6 minutes, only removed $75 \%$ of the plaque that the powered brush removed in 1 minute. Although one can argue the applicability of these particular data to direct patient use, there are additional studies that suggest that the electric toothbrush may prove advantageous for some patients. Several long-term ( 6 months or more) randomized controlled clinical trials have shown clinical benefits for certain powered brush designs compared with a manual brush in different populations with different levels of oral hygiene instruction. $\underline{30}, \underline{31}, \underline{32}, \underline{33}, \underline{34}, \underline{35}$ The differences between manual and powered brushing are more evident when oral hygiene instruction is provided and reinforced during these long-term trials.

In perhaps the most comprehensive 6-month comparative clinical trial between a manual and a powered brush (oscillating/rotating type), Haffajee and coworkers $\underline{36}, \underline{37}$ showed significantly better reduction in gingival index and attachment levels for the powered brush group, with mandibular and lingual surfaces showing the most benefit. They further demonstrated in both groups that a high level of personal supragingival plaque control had an unexpected and substantial beneficial effect on the subgingival flora. The decreased prevalence of periodontal pathogens from subgingival and supragingival plaque should lower the risk of periodontal disease initiation and recurrence. They further speculated that the lack of a significant microbiologic difference between the manual and the powered brush groups might be because the areas of greatest differences in clinical parameters (lingual and mandibular) were not the same areas that were sampled microbiologically (mesial-buccal site of each tooth).

Recently, two systematic reviews were published that addressed the comparative efficacy and safety of manual versus powered toothbrushing. Sicilia and coworkers $\frac{38}{3}$ concluded that the counter-rotational and the oscillating/rotating brushes can be more beneficial than a manual toothbrush in reducing the levels of gingival bleeding. A Cochrane Review noted that no powered toothbrush designs except for the oscillating/rotating action were consistently superior to manual brushing. It was found that the oscillating/rotating brush achieves a modest reduction in plaque and gingivitis compared with manual toothbrushing and that it is safe to use. $\frac{39}{}$ The long-term implications of these findings are unknown.

There are limited data regarding the compliance of powered toothbrush use in periodontitis patients. Stalnacke and coworkers $\underline{40}$ found a $62 \%$ rate of daily compliance by maintenance patients at least 3 years after obtaining a powered brush. Only 3\% had stopped using the powered brush altogether. In a study that specifically assessed low-compliance periodontal maintenance patients, another group showed an improved level of plaque control over 12 to 36 months in subjects using a powered brush. ${ }^{41}$ Additional long-term studies would be useful.

More recently, McCracken et al. $\stackrel{42}{ }$ recruited a small population of untreated periodontitis patients into a short-term powered toothbrush compliance study. Using a microelectronic device within each brush to record duration and pressure, the investigators gained further insight into powered toothbrush home use. Subjects were informed that the device would measure toothbrush performance only. No details were given as to what this meant in terms of 
their compliance. McCracken et al. $\underline{42}$ found that over 2 months of use, only about one third of these patients were truly compliant in using the brush for 2 minutes twice a day, nearly one third of the subjects overused the brush, and approximately one third substantially underused the brush. These data suggest that most but not all periodontitis patients using a powered brush are compliant. Patient education and motivation, as expected, play the greatest role in personal mechanical plaque control.

The plaque removal efficacy of the powered brush appears to come primarily from more efficient plaque removal on buccal and lingual approximal surfaces, with the problem of interproximal plaque removal still unresolved. $\underline{-33}$ Clearly, although powered brushes are more efficient at plaque removal, maximum benefit can only be achieved by proper instruction and patient motivation.

\section{Interdental cleaning}

Based on current knowledge, it seems reasonable to conclude that some form of regular interdental cleaning is necessary to maintain periodontal health because no toothbrush effectively disrupts true interproximal plaque, particularly in the posterior dentition. In addition, there is a clear interdental site predilection for gingivitis, periodontitis, and smooth-

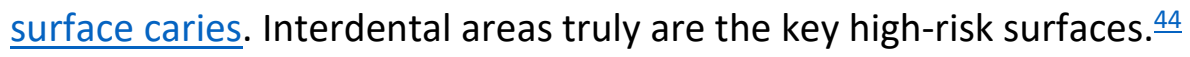

There are many different types of interdental cleaning aids, but the most widely recommended is dental floss or tape. Floss is most useful in the nonperiodontitis patient who has full interdental papillae and no exposed concave root surfaces. When used properly, it can penetrate the interproximal sulcus approximately 2 to $3 \mathrm{~mm}$. Axelsson et al. $\frac{45}{\mathrm{recommended}}$ that flat, fluoridated dental tape be used before brushing with a fluoridated toothpaste in children and young adults. It is unfortunate that traditional manual flossing is not an easy skill for patients to learn; it has been reported that only $20 \%$ of subjects report effective flossing behavior. ${ }^{46}$ Even in those who have been adequately trained and who can demonstrate skill retention after 1 year, there is still a substantial drop-off in daily plaque removal with time. $\frac{47}{4}$ Flossing forks, superfloss and, more recently, powered flossers have been introduced to make it easier for patients to clean interproximally. The studies that have been done on these interdental devices do not have enough statistical power to show anything but equivalence.

Interproximal brushes are better alternatives for periodontitis maintenance patients who have lost interdental papillae height and who are in a secondary preventive stage. $\frac{45}{\text { Interdental }}$ brushes come in a range of sizes. It seems reasonable to assume that the largest size that fits the space being deplaqued would be the most efficacious; however, this has not been proved. $\underline{48}$ Considering the range of sizes needed for any given patient, it may be best to choose the size that can be used in all high-risk sites. Advantages of this type of brush include the ability to deliver topical antimicrobials or fluorides to interproximal sites while mechanically removing plaque and to provide positive stimuli to the fibroblasts in the col area. This latter benefit is speculative and is an extrapolation from recent studies in a canine model. $\underline{49}, \underline{50, \underline{1}}$ 
Fluoridated triangular toothpicks have also proved to be an excellent way to deplaque the interproximal areas up to 2 to $3 \mathrm{~mm}$ subgingivally and have been recommended as part of a needs-related oral hygiene regimen for patients with treated periodontitis as part of a secondary prevention program. $\underline{45}$

Single-tufted brushes and rubber-tipped stimulators tend to be site specific. They are most often recommended for furcations, tipped teeth, the distals of terminal molars, or tooth surfaces directly adjacent to edentulous sites.

\section{Chemical plaque control}

\section{Mouthrinses}

Chemical preventive agents have been incorporated into oral disease management for centuries; however, it is only recently that these adjunctive therapies have been scientifically studied. Recently, Addy 52 wrote a brief, informative, and rather humorous review on antiseptic use in periodontal therapy. These agents should be viewed as adjuncts and not replacements for effective mechanical plaque control. They are preventive agents, not therapeutic agents. Given that many patients cannot maintain adequate levels of plaque control using mechanical oral hygiene methods alone, chemical plaque control has become a big business. Despite some over-reaching advertisements about the efficacy of some of the currently available antiseptics for plaque control, the dental profession can be thankful for the widespread public education that is occurring on the dangers of interproximal plaque. This section emphasizes developments in the area of chemical plaque control since the last World Workshop in Periodontics. $\underline{53}$

The biofilm inhibitory concentrations for a given antimicrobialare generally orders of magnitude higher than the standard minimal inhibitory concentrations determined for planktonic (freefloating) organisms. A recent in vitro study compared the antimicrobial activity of three mouthrinses with planktonic bacteria and their corresponding monospecies biofilms. $\frac{54}{A s}$ anticipated, the bacteria contained in biofilms were shown to have a decreased susceptibility to antimicrobial agents versus those in planktonic form. The antimicrobial mouthrinses included in the study were an essential-oil (EO)-containing mouthrinse (Listerine Antiseptic; Pfizer, Morris Plains, New Jersey), an amine fluoride/stannous fluoride-containing mouthrinse (Meridol), a triclosan and polyvinylmethyl ether/maleic acid copolymer-containing mouthrinse (Plax), and a negative control (phosphate-buffered saline). All three mouthrinses produced statistically significant (99.99\%) reductions in planktonic strains compared with the control. Effects on the biofilm forms of the organisms, however, were more variable. Exposure to Listerine Antiseptic produced statistically significant reductions compared with the control, whereas Plax (Colgate Palmolive [UK] Ltd., Guildford, United Kingdom) and Meridol (Wybert $\mathrm{GmbH}$, Lorrach, Germany) produced much smaller reductions that were not statistically significant. These in vitro results provide a clear demonstration of the resistance to antimicrobial agents conferred by biofilms. The results also provide additional support for employment of tests using biofilms to more accurately assess the relative activities of 
antiplaque agents in vitro (although when tested in vivo, there are even more obstacles to overcome).

The in vivo use of an EO-containing antiseptic mouthrinse has a long clinical history (Listerine). The active ingredient of this mouthrinse is a fixed combination of EOs $(0.064 \%$ thymol, $0.092 \%$ eucalyptol, $0.060 \%$ methyl salicylate, and $0.042 \%$ menthol). Many short-term (4-6 weeks) and long-term (3-6 months) clinical studies have demonstrated the effectiveness of EO rinses in plaque and gingivitis reduction. Although the "gold standard" for antiplaque and antigingivitis mouthrinsing is still chlorhexidine, $\underline{55}, \underline{56}$ the use of an EO rinse as an adjunct to mechanical oral hygiene can be beneficial, particularly in the secondary preventive phase because it does not induce calculus formation, taste alteration, or extrinsic tooth stain like chlorhexidine. $\underline{57}, \underline{58,59}$

In a 6-month supervised-use trial specifically designed to compare the antiplaque and antigingivitis efficacy of EO and chlorhexidine mouthrinses, Overholser et al. $\underline{60}$ showed significant reduction in plaque formation and in gingivitis compared with a negative control. Although both mouthrinses had comparable antigingivitis effectiveness, the chlorhexidine mouthrinse was significantly more effective than the EO-containing mouthrinse in reducing plaque. In addition, the chlorhexidine group had more extrinsic tooth stain and calculus than the EO or the control group. $\underline{60}$ Charles and coworkers $\underline{61}$ recently presented similar results in a 6 month randomized controlled clinical study on the antiplaque and the antigingivitis effects of a chlorhexidine or EO rinse compared with control. Although the patients were randomly assigned to the groups, it is difficult to discern how the observers remained masked to the treatments, given the obvious presence of stain and calculus. The investigators also stated that there was a statistically significant difference between the chlorhexidine group and the EO group at 3 months, but toward the end of the study ( 6 months), there was no difference. The chlorhexidine rinse group had significantly higher calculus formation and extrinsic tooth stain compared with the EO rinse group or the control group.

Because the occurrence of extrinsic tooth stain and calculus deposits may limit patient compliance, especially for long-term use, chlorhexidine mouthrinses have greater utility when short-term plaque control is critical. This situation includes the postoperative phase following periodontal surgery, when mechanical oral hygiene is difficult. The use of an EO rinse is better suited as a long-term plaque-control adjunct for moderate- to high-risk patients for primary and secondary prevention. For patients with physical disabilities that limit their mechanical oral hygiene skills, a chlorhexidine spray may prove useful. $\underline{52}$

The literature presents few studies that compare the efficacy of toothbrushing with interproximal plaque control using dental flossing or interproximal dental brushing $\underline{62,63,64}$ or

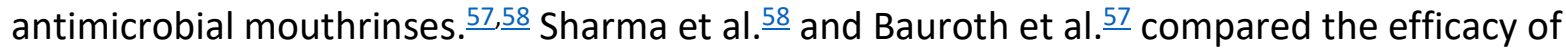
plaque removal using an EO-containing mouthrinse or dental flossing in addition to brushing. They included three groups in a parallel-arm, single-masked, randomized controlled clinical trial. The first group received the EO mouthrinse twice a day as an adjunct to the patient's regular twice daily brushing with a fluoride dentifrice, the second group was advised to floss 
once daily in conjunction with brushing, and the third group received a control mouthrinse to supplement brushing. The results showed significant improvement for the EO rinse and the dental floss group compared with baseline measurements. Reduction in the interproximal modified gingival index scores was "at least as good as" that provided by flossing. Although these studies were well controlled and well designed, the measurement of interproximal plaque seems problematic because the flossing group showed significantly less reduction compared with other studies that investigated the additional interproximal plaque reduction benefit comparing brushing alone to brushing and flossing. $\underline{64}, \underline{65}, \underline{66}, \underline{67}, \underline{68}$ In other words, the positive control (brushing and flossing) was not as positive as one might have expected; the reason for this is not clear in the study. Possible factors could be the length of this study compared with others. Patient compliance may have waned by the first 3-month visit, leading to poor flossing technique or a decrease in patient motivation. It should also be noted that methods for measuring true interproximal plaque are limited.

A follow-up study compared a combination of mechanical and chemical hygiene regimens. The experimental group was instructed to brush twice a day (B), floss daily (F), and rinse with the antiseptic twice daily (EO). This BFEO group represented optimal mechanical and chemical plaque control. A second group used a control mouthrinse (C) in conjunction with brushing and flossing (BFC group). A final group was assigned to brush and to use the placebo mouthrinse as a negative control $(B C)$. A significant reduction in mean modified gingival index and plaque index was seen for the experimental group (BFEO) compared with the other two groups. The investigators suggested that the combined mechanical disruption of the interproximal plaque followed by the EO rinse provides a synergistic effect in plaque and gingivitis reduction due to better biofilm penetration. There was little comment on the low incremental reduction for interproximal mean plaque index and modified gingival index from the $\mathrm{BC}$ and $\mathrm{BFC}$ groups or on the sharp drop from 3 to 6 months in the BFC group interproximal scores.

As promising as these data are, it would be even more helpful to carry out similar studies on moderate- to high-risk patients because it has been suggested that antiseptic rinsing is not costeffective for the general population. Recommending widespread antiseptic rinsing for the general population is essentially vast overtreatment to reduce disease only in the subpopulation of susceptible patients. $\underline{52}$

\section{Toothpaste}

Although the use of chlorhexidine as a mouthrinse has demonstrated significant plaque reduction, the incorporation of this agent into a dentifrice has proved difficult due to the interaction between chlorhexidine and calcium ions or anionic detergents such as sodium lauryl sulfate. ${ }^{69,70}$

The use of antigingivitis dentifrices has been recommended for primary prevention and as a maintenance measure as part of secondary prevention in treated and maintained periodontal patients. The addition of triclosan (a broad-spectrum phenol-derived antibacterial agent) to 
different dentifrice formulations has been studied in various short- and long-term trials. Volpe et al. $\underline{71}$ reviewed the use of various combinations of triclosan in reducing plaque and gingivitis in susceptible individuals.

One of the available combinations of triclosan is composed of $0.3 \%$ triclosan, $2.0 \%$ copolymer, and $\mathbf{0 . 2 4 3 \%}$ sodium fluoride (Colgate Total; Colgate Palmolive Co., New York, New York). This combination was shown to alter the quality and composition of subgingival plaque. $\underline{72}, \underline{73}$

A significant 5 -year study by Cullinan et al. $\underline{74}$ supported and expanded the previous findings. This double-blind controlled clinical trial examined the effect of the same triclosan formulation as the previous studies on the progression of periodontal disease in patients with attachment loss $\geq 2 \mathrm{~mm}$. It was concluded that the use of such a dentifrice significantly slowed the progression of periodontal disease in those individuals with existing disease. The clinical effect of a triclosan-containing dentifrice indicates that after a periodontal pocket has developed in a susceptible individual, the use of such dentifrice slows the progression of further pocket development. The effectiveness of triclosan dentifrice as a primary preventive measure against periodontitis has not been demonstrated; however, it has been used to prevent gingivitis, which is the necessary precursor to periodontitis.

One of the side effects of a triclosan dentifrice is tooth staining. A similar problem has been noted with more recent stable formulations of a stannous fluoride-containing dentifrice with proven antiplaque effects. $\underline{75, \underline{76}}$

\section{Irrigation}

The effect of supragingival oral irrigation in periodontal therapy is to flush away loosely attached bacteria present in the gingival crevice, thereby diminishing the potential for developing gingivitis. There is contradictory evidence about the usefulness of supragingival irrigation in reducing plaque formation. Although a few studies have shown some benefits of oral irrigation (professionally applied and as a part of a home care program), the benefits have been unimpressive. $\stackrel{77}{ }$ Recently, an improvement was demonstrated using this therapy at the clinical and subclinical level in a short-term daily home use study in periodontal patients. These results suggest that oral irrigation with water as part of a regular oral hygiene program can decrease the concentration of pro-inflammatory cytokinesin gingival fluids. $\underline{78}$ Although these are promising findings, more work needs to be done before a strong recommendation can be made to add such a regimen to daily home care for these patients. One must weigh the benefit against the cost of the therapy. There is also the possibility of poor long-term compliance.

\section{Clinical considerations for optimal prevention}

For patients having resistance to periodontitis and who would thus be classified as low risk based on currently available risk prediction instruments, it is not clear how much mechanical and chemical preventive therapy represents overtreatment. Likewise, for primary or secondary prevention in moderate- to high-risk "susceptible" patients, there is very little understanding of 
what may constitute the minimal effective therapy. The best available evidence compels us to continue to try to achieve "complete" plaque control by whatever means are best suited for the patient. For a toothbrushing population such as in the United States, this means there is more need for education and motivation in needs-related personal and professional gingivalplaque removal (supra- and subgingivally), with an emphasis on interproximal plaque removal in highrisk sites. Axelsson and colleagues ${ }^{44,45}$ suggest that encouraging patients to perform interproximal plaque control on the posterior "key risk teeth" before toothbrushing may be adequate in achieving prevention because the behavior is linked with an already wellestablished brushing habit. In high-risk patients in a secondary prevention program, the authors believe it is wise to consider a powered toothbrush for home use. When there are no allergies or other contraindications, a personal chemical plaque control regimen with a triclosancontaining toothpaste and perhaps an EO-containing mouthrinse twice daily would provide a cost-effective, evidence-based approach to prevention. Other adjunctive home care approaches for the high-risk patient include a dilute sodium hypochlorite solution (1 teaspoon household bleach/250 $\mathrm{mL}$ tap water) for subgingival irrigation as recommended by Slots et al. $\underline{79}$ As an adjunct to the professional supportive periodontal therapy, the use of a 1:9 ratio of povidone-iodine to water in the ultrasonic unit has also proved useful, particularly for advanced chronic or aggressive periodontitis cases. $\underline{79}$ When implants are present, plastic-tipped ultrasonics are preferred and metal instruments must be avoided.

Continuous multilevel risk assessment and management is now the standard of care. Clinicians must counsel patients on their risk profile and help them take decisive steps to reduce risk at each level. ${ }^{16}$ Perhaps the one area that could have the greatest overall public health benefit immediately is smoking cessation counseling.

Every dentist should be well familiar with the five "A's" of smoking cessation (Box 1) and the five first-line pharmacotherapies approved by the Food and Drug Administration for smoking cessation (Table 1). Clinicians must be willing to guide patients through this process. There is a new current dental terminology code (D1320) that is available for reimbursement, and each year more insurance plans are reimbursing for this service. Because the prevalence for adolescent smoking has risen dramatically since 1990, clinicians need to be proactive in discouraging adolescent and preadolescent patients from starting smoking. It is estimated that over 3000 additional teens and preteens become regular tobacco users each day. $\frac{80}{}$ It certainly makes sense for dental professionals to take a leading role in combating this chronic addiction because they see these patients more frequently than physicians.

\section{Box 1}

\section{The five "A's" for brief intervention}

1. Ask about tobacco use. Identify and document tobacco use status for every patient at every visit. 
2. Advise to quit. In a clear, strong, and personalized manner, urge every tobacco user to quit.

3. Assess willingness to make a quit attempt. Is the tobacco user willing to make a quit attempt at this time?

4. Assist in quit attempt. For the patient willing to make a quit attempt, use counseling and pharmacotherapy to help him or her quit.

5. Arrange follow-up. Schedule follow-up contact, preferably within the first week after the quit date.

Table 1. Suggestions for the clinical use of first-line pharmacotherapies approved for smoking cessation by the Food and Drug Administration

\begin{tabular}{|c|c|c|c|c|c|c|}
\hline Pharmacotherapy & Precautions/contraindications & $\begin{array}{l}\text { Side } \\
\text { effects }\end{array}$ & Dosage & Duration & Availability & Cost $/ d^{a}$ \\
\hline Bupropion SR & $\begin{array}{l}\text { History of seizure or history of } \\
\text { eating disorder }\end{array}$ & $\begin{array}{l}\text { Insomnia, } \\
\text { dry } \\
\text { mouth }\end{array}$ & $\begin{array}{l}\text { Begin } \\
\text { treatment } \\
1-2 \mathrm{wk} \\
\text { prequit } 150 \\
\mathrm{mg} \\
1 \times / \text { morning } \\
\text { for } 3 \mathrm{~d} \text { then } \\
150 \mathrm{mg} 2 \times / \mathrm{d}\end{array}$ & $\begin{array}{l}7-12 \text { wk } \\
\text { (up to } 6 \\
\text { mo) }\end{array}$ & $\begin{array}{l}\text { Zyban (prescription } \\
\text { only) }\end{array}$ & $\$ 3.33$ \\
\hline
\end{tabular}

\begin{tabular}{|c|c|c|c|c|c|c|}
\hline Nicotine gum & - & $\begin{array}{l}\text { Mouth } \\
\text { soreness, } \\
\text { dyspepsia }\end{array}$ & $\begin{array}{l}1-24 \text { cigs/d: } \\
2 \mathrm{mg} \text { gum } \\
\text { ( } \leq 24 \mathrm{pcs} / \mathrm{d}) \\
25+\text { cigs } / \mathrm{d}: 4 \\
\mathrm{mg} \text { gum } \\
\text { ( } \leq 24 \mathrm{pcs} / \mathrm{d})\end{array}$ & $\leq 12 \mathrm{wk}$ & $\begin{array}{l}\text { Nicorette/Nicorette } \\
\text { Mint (OTC only) }\end{array}$ & $\begin{array}{l}\$ 6.25 \text { for } \\
10 \text { (2-mg) } \\
\text { pieces, } \\
\$ 6.87 \text { for } \\
10 \text { (4-mg) } \\
\text { pieces }\end{array}$ \\
\hline
\end{tabular}




\begin{tabular}{|c|c|c|c|c|c|c|}
\hline Nicotine inhaler & - & $\begin{array}{l}\text { Local } \\
\text { irritation } \\
\text { of mouth } \\
\text { and } \\
\text { throat }\end{array}$ & $\begin{array}{l}6-16 \\
\text { cartridges/d }\end{array}$ & $\leq 6 \mathrm{mo}$ & $\begin{array}{l}\text { Nicotrol Inhaler } \\
\text { (prescription only) }\end{array}$ & $\begin{array}{l}\$ 10.94 \text { for } \\
10 \\
\text { cartridges }\end{array}$ \\
\hline $\begin{array}{l}\text { Nicotine nasal } \\
\text { spray }\end{array}$ & - & $\begin{array}{l}\text { Nasal } \\
\text { irritation }\end{array}$ & $\begin{array}{l}8-40 \\
\text { doses/d }\end{array}$ & 3-6 mo & $\begin{array}{l}\text { Nicotrol NS } \\
\text { (prescription only) }\end{array}$ & $\begin{array}{l}\$ 5.40 \text { for } \\
12 \text { doses }\end{array}$ \\
\hline Nicotine patch & - & $\begin{array}{l}\text { Local skin } \\
\text { reaction, } \\
\text { insomnia }\end{array}$ & $\begin{array}{l}21 \mathrm{mg} / 24 \mathrm{~h} \\
\text { then } 14 \\
\mathrm{mg} / 24 \mathrm{~h} \\
\text { then } 7 \\
\mathrm{mg} / 24 \mathrm{~h}\end{array}$ & $\begin{array}{l}4 \text { wk } \\
\text { then } 2 \\
\text { wk then } \\
2 \text { wk }\end{array}$ & $\begin{array}{l}\text { Nicoderm CQ (OTC } \\
\text { only) and generic } \\
\text { patches } \\
\text { (prescription and } \\
\text { OTC) }\end{array}$ & $\begin{array}{l}\text { Brand } \\
\text { name: } \\
\$ 4.00- \\
\$ 4.50^{\mathrm{b}}\end{array}$ \\
\hline
\end{tabular}

Abbreviations: cigs, cigarettes; OTC, over the counter; pcs, pieces.

Information contained within this table is not comprehensive. Please see package insert for additional information. aCosts are based on retail prices of medication purchased in April 2000 at a national chain pharmacy located in Madison, Wisconsin.

bGeneric brands of the patch recently became available and may be less expensive.

Finally, dental care providers must assess the patient's disease status each time he or she returns for supportive periodontal therapy. Clinicians must use the data available from the medical history review, risk assessment, and clinical examination, including radiographs when taken. As part of the supportive periodontal therapy rotations at Marquette University School of Dentistry, the students are given a laminated card that lists some specific criteria they should employ to assess the stability or instability of their maintenance patients. These criteria are listed in Box 2. Application of objective criteria such as these in the general practitioner's office may provide a more rational approach to appropriate referrals to the periodontist. Based on a recent retrospective survey of changes in referral patterns to periodontal offices over the past 20 years, it seems that some guidelines are needed if the goal of helping the public to keep their teeth in a state of health, comfort, and function in an esthetically pleasing presentation $\underline{81}$ is to be reached. 
Box 2

Site- and patient-level criteria to consider in assessing the stability of periodontal maintenance patients

Inflammation as measured by bleeding on probing

Full mouth bleeding on probing $>15 \%$ suggests instability

Sites that consistently show bleeding on probing over time may be unstable

Sites that consistently show no bleeding on probing are likely stable

Probing depth measurements

Sites with a probing depth increase of $\geq 2 \mathrm{~mm}$ from baseline or previous visit are considered unstable

Number of significant periodontal pocket depths (10 or more sites with $\geq 4 \mathrm{~mm}$ probing depth are considered unstable)

Probing depth $\geq 6 \mathrm{~mm}$ at any site is considered unstable

Progressive gingival recession from baseline or previous charting

Radiographic considerations

Loss of crestal bone height based on vertical bite wings is considered unstable

Consistent presence of crestal lamina dura suggests stability

Patient-level considerations

Poor hygiene in the presence of attachment loss plaque index $>30 \%$ is

considered unstable

Smoking more than one-half pack per day is considered unstable

Diabetes mellitus with HBA1C $\geq 9$ is considered unstable

High-stress events, divorce, loss of a loved one, and unemployment are considered unstable

\section{Future preventive strategies}

Vaccine development for periodontitis is a possible protection strategy for primary prevention. Different groups have been developing vaccines that target important surface structures of certain periodontopathogens. These surface structures include the fimbrial protein and hemagglutinating subunits necessary for adhesion and colonization of Porphyromonas gingivalis and the surface cysteine proteinases Arg- and Lys-gingipains that allow $P$ gingivalis to bind to and degrade host tissues, causing destruction by way of a prostaglandin $E_{2}$-dependent

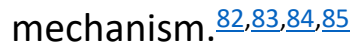

New drug delivery systems are also in development that should provide more cost-effective, slow-release antimicrobials and anti-inflammatory agents for primary prevention in high-risk subjects and secondary prevention in more moderate- to low-risk cases. The possibility of using these systems to deliver antimicrobial, anti-inflammatory, or immune-modulating agents is currently being tested. $\frac{86,87}{67}$ 
Another somewhat futuristic approach to primary or secondary prevention involves introducing nonpathogenic bacterial competitor strains (bacterial replacement therapy) as a means to prevent the colonization and establishment of pathogenic strains of bacteria. To date, most work done in this area has been geared toward dental caries rather than periodontal disease; however, progress has been made in construction of a nonpathogenic Streptococcus mutans strain that can colonize the oral cavity but has no ability to produce acid due to

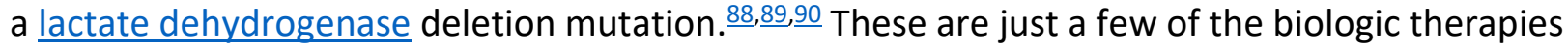
making their way into clinics. Considering how far we have come in 50 years, it is truly an exciting time to be a dentist.

\section{Acknowledgments}

The authors thank Julayne Erz for her expert assistance and Timothy Creamer, MD, for his helpful comments in the preparation of this manuscript.

\section{References}

${ }^{1}$ R. Andersen, M. Marcus, M. Mahshigan A comparative systems perspective on oral health promotion and disease prevention L.K. Cohen, H.C. Gift (Eds.), Disease prevention and oral health promotion, Munksgaard, Copenhagen (Denmark) (1995), pp. 307-340

2BBaehni PC, Bourgeois DM. Epidemiology of periodontal health and disease. Paper presented at the Proceedings of the European Workshop on Mechanical Plaque Control. Berne (Switzerland), May 9-12, 1998.

3H.G. Petersson, D. Bratthall The caries decline: a review of reviews Eur J Oral Sci, 104 (1996), pp. 436-443

${ }^{4} \mathrm{P}$. Axelsson, J. Lindhe Effect of controlled oral hygiene procedures on caries and periodontal disease in adults. Results after 6 years J Clin Periodontol, 8 (3) (1981), pp. 239-248

${ }_{5}^{5}$. Axelsson, J. Lindhe, B. Nystrom On the prevention of caries and periodontal disease. Results of a 15-year longitudinal study in adults J Clin Periodontol, 18 (3) (1991), pp. 182-189

${ }^{6} \mathrm{P}$. . Axelsson, B. Nystrom, J. Lindhe The long-term effect of a plaque control program on tooth mortality, caries and periodontal disease in adults. Results after $\mathbf{3 0}$ years of maintenance J Clin Periodontol, 31 (9) (2004), pp. 749-757

7C.D. Marshall-Day, R.G. Stephens, L.F. Quigley Periodontal disease: prevalence and incidence J Periodontol, 26 (1955), pp. 185-203

8 R.C. Page Periodontal diseases: a new paradigm J Dent Educ, 62 (10) (1998), pp. 812-821

9j. Lindhe, S.E. Hamp, H. Loe Plaque induced periodontal disease in beagle dogs. A 4-year clinical, roentgenographical and histometrical study J Periodontal Res, 10 (5) (1975), pp. 243-255

10L.J. Brown, H. Loe Prevalence, extent, severity and progression of periodontal disease Periodontol 2000, 2 (1993), pp. 57-71 
11. Haber, J. Wattles, M. Crowley, et al. Evidence for cigarette smoking as a major risk factor for periodontitis J Periodontol, 64 (1) (1993), pp. 16-23

12S.G. Grossi, J.J. Zambon, A.W. Ho, et al. Assessment of risk for periodontal disease. I. Risk indicators for attachment loss J Periodontol, 65 (3) (1994), pp. 260-267

$\underline{13}$ R.C. Oliver, T. Tervonen Diabetes-a risk factor for periodontitis in adults? J Periodontol, 65 (Suppl 5) (1994), pp. 530-538

${ }_{14} \mathrm{P}$. Meisel, A. Siegemund, R. Grimm, et al. The interleukin-1 polymorphism, smoking, and the risk of periodontal disease in the population-based SHIP study J Dent Res, 82 (3) (2003), pp. 189-193

15.M. Last A dictionary of epidemiology (4th edition), Oxford University Press, Oxford (England) (2001)

16N.P. Lang, U. Bragger, G. Salvi, et al. Supportive periodontal therapy (SPT) J. Lindhe, T. Karring, N.P. Lang (Eds.), Clinical periodontology and implantology (4th edition), Blackwell Munksgaard, Oxford (England) (2003), pp. 781-802

17Parameters of care American Academy of Periodontology J Periodontol, 71 (5 Suppl) (2000) iii, 847-83

18 Position paper periodontal maintenance J Periodontol, 74 (9) (2003), pp. 1395-1401

${ }_{19}^{19}$ D.W. Schutte, T.G. Donley Determining periodontal risk factors in patients presenting for dental care J Dent Hyg, 70 (6) (1996), pp. 230-234

$\underline{20}$ G.R. Persson, R. Attstrom, N.P. Lang, et al. Perceived risk of deteriorating periodontal conditions J Clin Periodontol, 30 (11) (2003), pp. 982-989

${ }^{21}$ G. R. Persson, L.A. Mancl, J. Martin, et al. Assessing periodontal disease risk: a comparison of clinicians' assessment versus a computerized tool J Am Dent Assoc, 134 (5) (2003), pp. 575-582

22R.C. Page, E.A. Krall, J. Martin, et al. Validity and accuracy of a risk calculator in predicting periodontal disease J Am Dent Assoc, 133 (5) (2002), pp. 569-576

$\underline{23}$ R.C. Page, J. Martin, E.A. Krall, et al. Longitudinal validation of a risk calculator for periodontal disease J Clin Periodontol, 30 (9) (2003), pp. 819-827

${ }^{24} \mathrm{H}$. Greenwell, N.F. Bissada Emerging concepts in periodontal therapy Drugs, 62 (18) (2002), pp. 2581-2587

${ }^{24}$ aLegonJ. Toothbrush trounces car as top invention. Available at: http://www.cnn.com/2003/TECH/ptech/01/22/toothbrush.king. Accessed May 6, 2005.

${ }^{25} \mathrm{~J}$ epsen S. The role of manual toothbrushes in effective plaque control. Paper presented at the Proceedings of the European Workshop on Mechanical Plaque Control. Berne (Switzerland), May 9-12, 1998.

$\underline{26}$ B.F. Hawkins, F.J. Kohout, P.A. Lainson, et al. Duration of toothbrushing for effective plaque control Quintessence Int, 17 (6) (1986), pp. 361-365

27D. Beals, T. Ngo, Y. Feng, et al. Development and laboratory evaluation of a new toothbrush with a novel brush head design Am J Dent, 13 (Spec No) (2000), pp. 5A-14A 
${ }^{28}$ G.A. Van der Weijden, M.F. Timmerman, A. Nijboer, et al. A comparative study of electric toothbrushes for the effectiveness of plaque removal in relation to toothbrushing duration.Timerstudy J Clin Periodontol, 20 (7) (1993), pp. 476-481

${ }^{29} G$.A. Van der Weijden, M.F. Timmerman, I. Snoek, et al. Toothbrushing duration and plaque removal efficacy of electric toothbrushes Am J Dent, 9 (1996), pp. 31-36

${ }^{30}$ D.A. Baab, R.H. Johnson The effect of a new electric toothbrush on supragingival plaque and gingivitis J Periodontol, 60 (6) (1989), pp. 336-341

31S. Wilson, D. Levine, G. Dequincey, et al. Effects of two toothbrushes on plaque, gingivitis, gingival abrasion, and recession: a 1-year longitudinal study Compend Suppl (16) (1993), pp. S569-S579

32R.A. Yukna, R.L. Shaklee Evaluation of a counter-rotational powered brush in patients in supportive periodontal therapy J Periodontol, 64 (9) (1993), pp. 859-864

${ }_{33}$ G.A. Van der Weijden, M.F. Timmerman, et al. The long-term effect of an oscillating/rotating electric toothbrush on gingivitis. An 8-month clinical study J Clin Periodontol, 21 (2) (1994), pp. 139-145

34J. Ainamo, Q. Xie, A. Ainamo, et al. Assessment of the effect of an oscillating/rotating electric toothbrush on oral health. A 12-month longitudinal study J Clin Periodontol, 24 (1) (1997), pp. 28-33

35A.R. Dentino, G. Derderian, M. Wolf, et al. Six-month comparison of powered versus manual toothbrushing for safety and efficacy in the absence of professional instruction in mechanical plaque control J Periodontol, 73 (7) (2002), pp. 770-778

${ }^{36}$ A.D. Haffajee, C. Smith, G. Torresyap, et al. Efficacy of manual and powered toothbrushes (II). Effect on microbiological parameters J Clin Periodontol, 28 (10) (2001), pp. 947-954

${ }^{37}$ A.D. Haffajee, M. Thompson, G. Torresyap, et al. Efficacy of manual and powered toothbrushes (I). Effect on clinical parameters J Clin Periodontol, 28 (10) (2001), pp. 937-946

$\underline{38}$ A. Sicilia, I. Arregui, M. Gallego, et al. A systematic review of powered vs manual toothbrushes in periodontal cause-related therapy J Clin Periodontol, 29 (Suppl

3) (2002), pp. 39-54 [discussion: 90-1]

${ }^{39} \mathrm{M}$. Heanue, S.A. Deacon, C. Deery, et al. Manual versus powered toothbrushing for oral health Cochrane Database Syst Rev, 1 (2003) CD002281

${ }^{40} \mathrm{~K}$. Stalnacke, B. Soderfeldt, B. Sjodin Compliance in use of electric toothbrushes Acta Odontol Scand, 53 (1) (1995), pp. 17-19

$\underline{41} \mathrm{~K}$. Hellstadius, B. Asman, A. Gustafsson Improved maintenance of plaque control by electrical toothbrushing in periodontitis patients with low compliance $J$ Clin Periodontol, 20 (4) (1993), pp. 235-237

$\underline{42}$ G.I. McCracken, J. Janssen, N. Steen, et al. A clinical evaluation of a novel data logger to determine compliance with the use of powered toothbrushes $J$ Clin Periodontol, 29 (9) (2002), pp. 838-843 
43Van der Weijden GA, Timmerman MF, Danser MM, et al. The role of electric toothbrushes: advantages and limitations. Paper presented at the Proceedings of the European Workshop on Mechanical Plaque Control. Berne (Switzerland), May 9-12, 1998.

${ }^{44}$ Axelsson P. Needs-related plaque control measures based on risk prediction. Paper presented at the Proceedings of the European Workshop on Mechanical Plaque Control. Berne (Switzerland), May 9-12, 1998.

45.P. Axelsson, J.M. Albandar, T.E. Rams Prevention and control of periodontal diseases in developing and industrialized nations Periodontol 2000, 29 (2002), pp. 235-246

46 W.P. Lang, M.M. Farghaly, D.L. Ronis The relation of preventive dental behaviors to periodontal health status J Clin Periodontol, 21 (3) (1994), pp. 194-198

47J.E. Stewart, G.R. Wolfe The retention of newly-acquired brushing and flossing skills J Clin Periodontol, 16 (5) (1989), pp. 331-332

48 Kinane DF. The role of interdental cleaning in effective plaque control: need for interdental cleaning in primary and secondary prevention. Paper presented at the Proceedings of the European Workshop on Mechanical Plaque Control. Berne (Switzerland), May 9-12, 1998.

$\underline{49}$ T. Sakamoto, M. Horiuchi, T. Tomofuji, et al. Spatial extent of gingival cell activation due to mechanical stimulation by toothbrushing J Periodontol, 74 (5) (2003), pp. 585-589

${ }^{50} \mathrm{~T}$. Tomofuji, M. Morita, M. Horiuchi, et al. The effect of duration and force of mechanical toothbrushing stimulation on proliferative activity of the junctional epithelium. $J$ Periodontol, 73 (10) (2002), pp. 1149-1152

51T. Tomofuji, D. Ekuni, T. Yamamoto, et al. Optimum force and duration of toothbrushing to enhance gingival fibroblast proliferation and procollagen type I synthesis in dogs $J$ Periodontol, 74 (5) (2003), pp. 630-634

$52 \mathrm{M}$. Addy The use of antiseptics in periodontal therapy J. Lindhe, T. Karring, N.P. Lang (Eds.), Clinical periodontology and implantology (4th edition), Blackwell Munksgaard, Oxford (England) (2003), pp. 464-493

53E.B. Hancock Periodontal diseases: prevention Ann Periodontol, 1 (1) (1996), pp. 223-249

54D.H. Fine, D. Furgang, M.L. Barnett Comparative antimicrobial activities of antiseptic mouthrinses against isogenic planktonic and biofilm forms of Actinobacillus actinomycetemcomitans J Clin Periodontol, 28 (7) (2001), pp. 697-700

${ }_{55}^{5}$ N.P. Lang, P. Hotz, H. Graf, et al. Effects of supervised chlorhexidine mouthrinses in children. A longitudinal clinical trial J Periodontal Res, 17 (1) (1982), pp. 101-111

${ }^{56}$ C.P. Ernst, K. Prockl, B. Willershausen The effectiveness and side effects of $0.1 \%$ and $0.2 \%$ chlorhexidine mouthrinses: a clinical study Quintessence Int, 29 (7) (1998), pp. 443-448

57K. Bauroth, C.H. Charles, S.M. Mankodi, et al. The efficacy of an essential oil antiseptic mouthrinse vs. dental floss in controlling interproximal gingivitis: a comparative study J Am Dent Assoc, 134 (3) (2003), pp. 359-365

$\underline{58}$ N.C. Sharma, C.H. Charles, J.G. Qaqish, et al. Comparative effectiveness of an essential oil mouthrinse and dental floss in controlling interproximal gingivitis and plaque $\mathrm{Am} J$ Dent, 15 (6) (2002), pp. 351-355 
${ }_{59} \mathrm{~N}$. Sharma, C.H. Charles, M.C. Lynch, et al. Adjunctive benefit of an essential oil-containing mouthrinse in reducing plaque and gingivitis in patients who brush and floss regularly: a six-month study J Am Dent Assoc, 135 (4) (2004), pp. 496-504

${ }^{60}$ C.D. Overholser, T.F. Meiller, L.G. DePaola, et al. Comparative effects of 2 chemotherapeutic mouthrinses on the development of supragingival dental plaque and gingivitis $\mathrm{J}$ Clin Periodontol, 17 (8) (1990), pp. 575-579

${ }^{61} \mathrm{C} . \mathrm{H}$. Charles, K.M. Mostler, L.L. Bartels, et al. Comparative antiplaque and antigingivitis effectiveness of a chlorhexidine and an essential oil mouthrinse: 6-month clinical trial J Clin Periodontol, 31 (10) (2004), pp. 878-884

$\underline{62}$ A. Bergenholtz, A. Bjorne, B. Vikstrom The plaque-removing ability of some common interdental aids. An intraindividual study J Clin Periodontol, 1 (3) (1974), pp. 160-165

63R.C. Graves, J.A. Disney, J.W. Stamm Comparative effectiveness of flossing and brushing in reducing interproximal bleeding J Periodontol, 60 (5) (1989), pp. 243-247

${ }^{64}$ R.D. Kiger, K. Nylund, R.P. Feller A comparison of proximal plaque removal using floss and interdental brushes J Clin Periodontol, 18 (9) (1991), pp. 681-684

65p. Finkelstein, E. Grossman The effectiveness of dental floss in reducing gingival inflammation J Dent Res, 58 (3) (1979), pp. 1034-1039

66 S.L. Fischman The history of oral hygiene products: how far have we come in 6000 years? Periodontol, 1997 (15) (2000), pp. 7-14

67N.A. Anderson, C.M. Barnes, C.M. Russell, et al. A clinical comparison of the efficacy of an electromechanical flossing device or manual flossing in affecting interproximal gingival bleeding and plaque accumulation J Clin Dent, 6 (1) (1995), pp. 105-107

${ }^{68}$ R.R. Lobene, P.M. Soparkar, M.B. Newman Use of dental floss. Effect on plaque and gingivitis Clin Prev Dent, 4 (1) (1982), pp. 5-8

69p. Barkvoll, G. Rolla, K. Svendsen Interaction between chlorhexidine digluconate and sodium lauryl sulfate in vivo J Clin Periodontol, 16 (9) (1989), pp. 593-595

70P. Gjermo, G. Rolla The plaque-inhibiting effect of chlorhexidine-containing dentifrices Scand J Dent Res, 79 (2) (1971), pp. 126-132

$\underline{71}$ A.R. Volpe, M.E. Petrone, W. De Vizio, et al. A review of plaque, gingivitis, calculus and caries clinical efficacy studies with a fluoride dentifrice containing triclosan and PVM/MA copolymer J Clin Dent, 7 (Suppl) (1996), pp. S1-S14

72R.P. Ellwood, H.V. Worthington, A.S. Blinkhorn, et al. Effect of a triclosan/copolymer dentifrice on the incidence of periodontal attachment loss in adolescents $J$ Clin Periodontol, 25 (5) (1998), pp. 363-367

73 B. Rosling, B. Wannfors, A.R. Volpe, et al. The use of a triclosan/copolymer dentifrice may retard the progression of periodontitis J Clin Periodontol, 24 (12) (1997), pp. 873-880

${ }^{74}$ M.P. Cullinan, B. Westerman, S.M. Hamlet, et al. The effect of a triclosan-containing dentifrice on the progression of periodontal disease in an adult population J Clin Periodontol, 30 (5) (2003), pp. 414-419

${ }^{75}$ R.L. Boyd Long-term evaluation of a SnF2 gel for control of gingivitis and decalcification in adolescent orthodontic patients Int Dent J, 44 (1 Suppl 1) (1994), pp. 119-130 
${ }^{76}$ D.J. White A "return" to stannous fluoride dentifrices J Clin Dent, 6 (Spec No) (1995), pp. 2936

${ }^{77} \mathrm{G}$. Greenstein The role of supra- and subgingival irrigation in the treatment of periodontal diseases American Academy of Periodontology, Chicago (1995)

${ }^{78}$ C.W. Cutler, T.W. Stanford, C. Abraham, et al. Clinical benefits of oral irrigation for periodontitis are related to reduction of pro-inflammatory cytokine levels and plaque J Clin Periodontol, 27 (2) (2000), pp. 134-143

799. Slots, M.G. Jorgensen Effective, safe, practical and affordable periodontal antimicrobial therapy: where are we going, and are we there yet? Periodontol 2000, 28 (2002), pp. 298-312

${ }^{80}$ M.C. Fiore, W.C. Bailey, S.J. Cohen, et al. Treating tobacco use and dependence US Department of Health and Human Services, Rockville (MD) (2000)

${ }^{81}$ C.M. Cobb, A. Carrara, E. El-Annan, et al. Periodontal referral patterns, 1980 versus 2000: a preliminary study J Periodontol, 74 (10) (2003), pp. 1470-1474

${ }^{82}$ R.C. Page Vaccination and periodontitis: myth or reality J Int Acad Periodontol, 2 (2) (2000), pp. 31-43

${ }^{83}$ D. Vasel, T.J. Sims, B. Bainbridge, et al. Shared antigens of Porphyromonas gingivalis and Bacteroides forsythus Oral Microbiol Immunol, 11 (4) (1996), pp. 226-235

${ }_{84}$ B.W. Bainbridge, R.C. Page, R.P. Darveau Serum antibodies to Porphyromonas gingivalis block the prostaglandin E2 response to lipopolysaccharide by mononuclear cells Infect Immun, 65 (11) (1997), pp. 4801-4805

85 F.A. Roberts, L.S. Houston, S.A. Lukehart, et al .Periodontitis vaccine decreases local prostaglandin E2 levels in a primate model Infect Immun, 72 (2) (2004), pp. 1166-1168

86P. AntonyRaj, L. Rajkumar, A.R. Dentino New and novel technology for intra-oral delivery of antimicrobials J Dent Res, 83 (Spec Iss A) (2004), p. 1468

87P. AntonyRaj, A.R. Dentino A novel bifunctional molecule targets oral pathogens $J$ Dent Res, 82 (Spec Iss A) (2002), p. 3935

88 J.D. Hillman, A. Chen, M. Duncan, et al. Evidence that L-(+)-lactate dehydrogenase deficiency is lethal in Streptococcus mutans Infect Immun, 62 (1) (1994), pp. 60-64

89. D. Hillman Genetically modified Streptococcus mutans for the prevention of dental caries Antonie Van Leeuwenhoek, 82 (1-4) (2002), pp. 361-366

90 J.D. Hillman, M.J. Duncan, K.P. Stashenko Cloning and expression of the gene encoding the fructose-1, 6-diphosphate-dependent L-(+)-lactate dehydrogenase of Streptococcus mutans Infect Immun, 58 (5) (1990), pp. 1290-1295 